\title{
E-health literacy and associated factors among chronic patients in a low-income country: a cross-sectional survey
}

Kirubel Biruk Shiferaw ${ }^{1 *}$ D, Binyam Chakilu Tilahun², Berhanu Fikadie Endehabtu², Monika Knudsen Gullslett ${ }^{3}$ and Shegaw Anagaw Mengiste ${ }^{4}$

\begin{abstract}
Background: Chronic patients persistently seek for health information on the internet for medication information seeking, nutrition, disease management, information regarding disease preventive actions and so on. Consumers ability to search, find, appraise and use health information from the internet is known as eHealth literacy skill. eHealth literacy is a congregate set of six basic skills (traditional literacy, health literacy, information literacy, scientific literacy, media literacy and computer literacy). The aim of this study was to assess eHealth literacy level and associated factors among internet user chronic patients in North-west Ethiopia.

Methods: Institutional based cross-sectional study design was conducted. Stratified sampling technique was used to select 423 study participants among chronic patients. The eHealth literacy scale (eHEALS) was used for data collection. The eHEALS is a validated eight-item Likert scaled questionnaire used to asses self-reported capability of eHealth consumers to find, appraise, and use health related information from the internet to solve health problems. Statistical Package for Social science version 20 was used for data entry and further analysis. Multivariable logistic regression was used to examine the association between the eHealth literacy skill and associated factors. Significance was obtained at $95 \% \mathrm{Cl}$ and $p<0.05$.

Result: In total, 423 study subjects were approached and included in the study from February to May, 2019. The response rate to the survey was $95.3 \%$. The majority of respondents 268 (66.3\%) were males and mean age was $35.58 \pm 14.8$ years. The multivariable logistic regression model indicated that participants with higher education (at least having the diploma) are more likely to possess high eHealth literacy skill with Adjusted Odds Ratio (AOR): 3.48, $95 \% \mathrm{Cl}(1.54,7.87)$. similarly, being government employee AOR: 1.71, 95\% Cl $(1.11,2.68)$, being urban resident AOR: $1.37,95 \% \mathrm{Cl}(0.54,3.49)$, perceived good health status AOR: 3.97, 95\% Cl $(1.38,11.38)$, having higher income AOR: $4.44,95 \% \mathrm{Cl}(1.32,14.86)$, Daily internet use AOR: $2.96,95 \% \mathrm{Cl}(1.08,6.76)$, having good knowledge about the availability and importance of online resources AOR: $3.12,95 \% \mathrm{Cl}(1.61,5.3)$, having positive attitude toward online resources AOR: $2.94,95 \% \mathrm{Cl}(1.07,3.52)$ and higher level of computer literacy AOR: $3.81,95 \% \mathrm{Cl}(2.19,6.61)$ were the predictors positively associated with higher eHealth literacy level.

(Continued on next page)
\end{abstract}

\footnotetext{
* Correspondence: birukkirubel@gmail.com

'Health Informatics Department, Medicine and Health science college, Debre Markos University, Debre Markos, Ethiopia

Full list of author information is available at the end of the article
}

(c) The Author(s). 2020 Open Access This article is licensed under a Creative Commons Attribution 4.0 International License, which permits use, sharing, adaptation, distribution and reproduction in any medium or format, as long as you give appropriate credit to the original author(s) and the source, provide a link to the Creative Commons licence, and indicate if changes were made. The images or other third party material in this article are included in the article's Creative Commons licence, unless indicated otherwise in a credit line to the material. If material is not included in the article's Creative Commons licence and your intended use is not permitted by statutory regulation or exceeds the permitted use, you will need to obtain permission directly from the copyright holder. To view a copy of this licence, visit http://creativecommons.org/licenses/by/4.0/ The Creative Commons Public Domain Dedication waiver (http://creativecommons.org/publicdomain/zero/1.0/) applies to the data made available in this article, unless otherwise stated in a credit line to the data. 
(Continued from previous page)

Conclusion: Besides the mounting indication of efficacy, the present data confirm that internet use and eHealth literacy level of chronic patients in this setting is relatively low which clearly implicate that there is a need to fill the skill gap in eHealth literacy among chronic patients which might help them in finding and evaluating relevant online sources for their health-related decisions.

Keywords: eHealth literacy, Chronic patients, eHealth, Low income country, Electronic health

\section{Background}

Noncommunicable diseases (NCDs) are "also known as chronic diseases, which tend to be of extended period resulted from a combination of genetic, physiological, environmental and behavioral factors" [1]. According to the world health organization's (WHO) report in 2018, non-communicable diseases (NCDs) are accounted for the deaths of 41 million people each year, equivalent to $71 \%$ of all deaths globally [1]. In Ethiopia, 39\% of all deaths are estimated to be due to Non-communicable diseases [2]. Worldwide, Numerous activities and initiatives are undertaking to alleviate this huge number of incidence and death by one third as indicated in United Nations sustainable development goals (SDG) by 2030 [3]. Literatures depicted that patient empowerment and education focused on self-management and health promotion is very important $[4,5]$. Enabling patients to ask about their condition, to follow medication instructions, to improve their adherence and to enhance their engagement in the healthcare process is not an easy task. But, helping patients to help themselves is a key step in improving the overall health status and even in reducing the patient load in hospitals specially in low-income countries [6-8].

The development in internet access and the improvements in performance due to the new technologies makes the internet to be the focus of many new healthcare improvements $[9,10]$. Systematic reviews conducted in different chronic disease cases have steadily stated that eHealth interventions for people with chronic diseases have considerable impact on enhancing selfmanagement and patient engagement for their healthcare [11-14]. Despite of the limited number of studies from the perspective of chronic patients in middle and low-income countries, eHealth literacy is pointed in several literatures as one of the major skill required to be acquired by patients with chronic diseases if eHealth interventions are tailored to improve patient's selfmanagement and facilitating patient's engagement in the care service $[11,15,16]$. In addition to the low internet penetration in Ethiopia (15\%), the gap in skill to find and evaluate online resources is another challenge. EHealth literacy is defined as "one's ability to seek, find, understand, and appraise health information from electronic sources and apply the knowledge gained for addressing or solving a health problem." [17]. As the concept of eHealth literacy is a function of different set of skills, it is highly affected by multidimensional factors including sociocultural, economical and behavioral factors [18]. According to the Lily model, eHealth literacy is a congregate set of six basic skills (traditional literacy, health literacy, information literacy, scientific literacy, media literacy and computer literacy) [19]. The details of each components are available in the attached table as Additional file.

Although it is not mandatory to have a mastery in all the six literacy skills, the gap in any of these could be a constraint to benefit from eHealth merits. As a result, one has to have at least a moderate level of skills in all the literacies to make an effective use of the outrageous eHealth resources. To explore the eHealth literacy level and its associated factors in a population with chronic disease is more urgent and important now than ever. The lesson from COVID-19 thought the world that eHealth is not optional and luxurious approach to healthcare rather it is necessary, safer and effective way of providing healthcare service for both patients with underlying conditions and others during such times. The escalating number of internet users, information needs and smartphone penetration in African countries are the most important driving reasons ringing the relevance of assessing eHealth literacy \& factors thereof among patients to harness eHealth merits. Given the gap in literatures regarding chronic patients' eHealth literacy skill in Africa, conducting this study will contribute to the scientific knowledge in addressing the research question in this region. Hence, the aim of this study was to assess eHealth literacy level and associated factors among internet user chronic patients in University of Gondar comprehensive specialized hospital, North West Ethiopia.

\section{Methods}

\section{Study design and setting}

An institutional based cross-sectional study was conducted to assess eHealth literacy skill and associated factor among internet user chronic patients in University of Gondar comprehensive specialized hospital (UOGCSH). Gondar is placed $725-\mathrm{km}$ driving distance North-west from the capital Addis Ababa. The UOGCS hospital is 
the largest specialized teaching hospital in the Amhara region serving more than five million peoples annually. It provides a specialized care and follow up service for different chronic cases in different days of a week. According to the hospital's statistics, cardiovascular diseases like hypertension, chronic respiratory diseases like asthma, epilepsy and type 2 diabetes are the most common chronic disease morbidities in the hospital at the time when this study was conducted (2019).

\section{Sample size and procedure}

The sample size for this study was calculated using single population proportion formula [20] with $95 \%$ confidence level, proportion of eHealth literacy 50\% [21] since there were no previous study done in this study population in Ethiopia and relative precision to be $5 \%$. With $10 \%$ none-response rate, the total sample size calculated was 423 . The participants for this study was selected using a stratified random sampling method with proportional allocation technique. Stratified sampling is a method of sampling applied for a population with subsets of known size where the sub-sets make up different proportions of the whole [22]. Thus, it is appropriate to use stratified random sampling to have a representative sample of the population under study. Participants were approached randomly and the stratification was based on the most prevalent chronic diseases in University of Gondar Comprehensive Specialized Hospital (cardio vascular disease, chronic respiratory disease, diabetics, epilepsy and other chronic diseases were categorized as "other chronic diseases") hoping for an eHealth literacy difference among patients with different chronic cases [2].

\section{Data collection instrument and procedure}

Data was collected by using interviewer administered questionnaire from February to May 2019. The questionnaire requires $10-15 \mathrm{~min}$ to complete and had three parts. The first section contained questions about participant's socio demographic characteristics (10 items), the second part contained items related with internet use (6 items), knowledge about the availability and importance of online resources (5 items), attitude of participant to use online health resources (4), computer literacy (5 items) and the third section contained items related to eHealth literacy skill (8 items). Except for the first part (sociodemographic related items), all items were measured in 5-point Likert scale ranging from strongly agree (5) to strongly disagree (1). A validated tool was used to determine eHealth literacy skill which was developed by Norman and Skinner [23, 24]. The eHEALS (eHealth literacy scale) is an eight-item scale used to asses selfreported capability of eHealth consumers to find, appraise, and use health related information from the internet to solve health problems [23]. According to Norman and Skinner, the eHealth Literacy Scale (eHEALS) is a promising tool to evaluate users' ease and skills to use the internet in order to obtain health related information [19, 23]. Apart from the measurement tool coined by Norman and Skinner, researchers have also suggested and used a modified versions of the original eHEALS tailored to their context and variable of interest $[25,26]$. Moreover, researchers have also developed a novel measurement tools to assess eHealth Literacy [2729]. Yet the widely used and constantly validated measurement scale for consumers eHealth Literacy is the original eHEALS proposed by Norman and Skinner. The scale had been used in various studies in different populations exhibiting considerable reliability and validity of items [26, 30-36]. As the eHEALS aims to asses a wide-ranging summary of literacy skills, it is a potential instrument to evaluate the comprehensive literacy skill of eHealth consumers.

The items were translated to Amharic to avoid language barriers and the reliability of the translated items were assessed for its internal consistency by calculating Cronbach alpha coefficient among 30 chronic patients in other hospital (Bahirdar Felegehiwot Referral Hospital) [37]. Data collectors with minimum of diploma in Health Information Technician (HIT) were recruited and trained for data handling and related issues. Participants were approached for consent and data collection while they are on the queue waiting for their turn to see their doctors.

\section{Data quality control \& analysis methods}

A one-day training was delivered to data collectors by the investigator in regard with data handling and participants approach. Continuous and active supervision was done during the data collection and after data collection was completed, it was checked for completeness and accuracy. Finally, the data was entered using statistical package for social science (SPSS) software version 20 for further analysis.

Descriptive analysis was performed to summarize participant's socio-demographic characteristics. The extent of internet use, knowledge and attitude were described using frequency and percentages. Before running the logistic regression model, assumptions were checked for outliers, multicollinearity and independent error terms. Multicollinearity was tested by running a false linier regression iterating the independent variables as a dependent variable and the result showed all the variance inflation factor (VIF) value less than three and tolerance greater than 0.7 which demonstrated the absence of multicollinearity [38]. The data was also checked for outliers by box plot and no outshining outlier effect was observed. The models' goodness of fit was also checked 
using omnibus tests of model coefficients for overall (global) fitness of the model and Hosmer and Lemeshow test for fitness of the data to the model. Consequently, the omnibus test result was significant with $p$-value $<0.05$ and the Hosmer and Lemeshow test shows a good model fit with $p$-value $=0.608$, which signifies the goodness of the model [39]. A bivariate logistic regression was performed for each independent variable and a $p$-value $<0.2$ [40] was included in the final model. A multivariable logistic regression was fitted to identify significant factors $(P$-value $<0.05)$ associated with eHealth literacy skill. The strength of association was explained in terms of odds ratio (OR) and a $95 \%$ confidence interval $(\mathrm{CI})$.

\section{Result}

In total, 423 study subjects were approached and included in the study from March 02 to May 17, 2019. The response rate was $95.3 \%$. The majority of respondents $268(66.3 \%)$ were males and the mean age participants was $35.58 \pm 14.8$ years. A large number of respondents were diploma holders and above 208 $(51.5 \%)$. Most of the study participants were urban residents352 (87.1\%). About 150 (37.1\%) of the respondents were governmental employees. See (Table 1) for detail descriptive statistics.

\section{Internet use}

The result indicated a $47.0 \%$ daily internet use of chronic patients with $81.2 \%$ usage for browsing social media. About $95.8 \%$ of the participants reported that their major means of internet use was smartphone. Concurrently, $83.4 \%$ of those internet user chronic patients confirmed that their major sources of health information were health professionals followed by television broadcasts which was $30.0 \%$.

\section{eHealth literacy level}

The mean eHealth literacy score was 24.6 with a standard deviation of 6.4. Scores less than the median value was labeled as low eHealth literacy and scores greater than \& equal to the median value was labeled as high eHealth literacy level. Associated factors with $p$-value less than 0.25 from the bivariate analysis were included in the final multivariable logistic regression model to control the effect of confounding. Accordingly, the statistically insignificant results were Gender, marital status, type of chronic disease and number of medications. From the socio-demographic variables, age, educational status and residence were significantly associated with frequency of internet use where younger, educated and peoples from urban residence were more frequent users of internet. On the other hand, only educational status and residence were significantly associated with knowledge of participants about the availability and importance of online health information. Attitude of chronic patients towards using online sources were primarily associated with their educational status, residence and their monthly income. Whereas computer literacy was associated with Gender, marital status, frequency of internet use and knowledge about the availability and importance of online sources.

The multivariable logistic regression model indicated that participants holding diploma and above are more likely to possess high eHealth literacy skill with AOR: 3.48, 95\% CI $(1.54,7.87)$. similarly, being government employee AOR: $1.71,95 \%$ CI $(1.11,2.68)$, being urban resident AOR: $1.37,95 \% \mathrm{CI}(0.54,3.49)$, perceived good health status AOR: 3.97, 95\% CI $(1.38,11.38)$, having higher monthly income >5500ETB AOR: 4.44, 95\% CI (1.32, 14.86), being daily internet user AOR: $2.96,95 \%$ CI $(1.08,6.76)$, having good knowledge about the availability and importance of online resources AOR: 3.12, $95 \%$ CI $(1.61,5.3)$, having positive attitude toward using online resources AOR: $2.94,95 \% \mathrm{CI}(1.07,3.52)$ and higher level of computer literacy AOR: 3.81, 95\% CI $(2.19,6.61)$ were the predictors positively associated with higher eHealth literacy level. See Table 2 for detail.

\section{Discussion}

The purpose of this study was to determine the level of eHealth literacy skill and associated factors among internet user chronic patients in University of Gondar Comprehensive Specialized Hospital. The result showed that eHealth literacy skill was relatively low with 188 (46.5\%) of the participants reporting high eHealth literacy skill. The result also shows 353 (87.3\%) use of daily and several days a week internet use of participants with more than three fourth of them using it for browsing social medias like Facebook. Younger, educated and peoples from urban residence were more frequent users of internet. Educational status, occupation type, residence, selfreported health status, monthly salary, frequency of internet use, knowledge about the availability and importance of online resources, attitude toward using online resources and computer literacy level were statistically significant factors associated with eHealth literacy skill among internet user chronic patients in this study. This study also found that, the majority of respondents 268 (66.3\%) were males and there was no significant chi square difference among the groups which is different from a study which revealed that males are superior internet users [41]. This could be due to the fact that the participants in this study are all internet users. The mean age was $35.58 \pm 14.8$ years and when compared to elders, youngsters were more frequent internet users. This could be due to the internet penetration rate 
Table 1 Descriptive statistics of the participants socio-demographic and other variables

\begin{tabular}{|c|c|c|c|c|c|}
\hline Variable & $n$ & $\%$ & Variables & $n$ & $\%$ \\
\hline Age & & & Occupation type & & \\
\hline$<29$ & 203 & $50 \%$ & Governmental & 150 & $37.1 \%$ \\
\hline 30-49 & 110 & $27.4 \%$ & Private & 115 & $28.5 \%$ \\
\hline$>50$ & 91 & $22.6 \%$ & unemployed & 139 & $34.4 \%$ \\
\hline Gender & & & Residence & & \\
\hline Male & 268 & $66.3 \%$ & Rural & 52 & $12.9 \%$ \\
\hline Female & 136 & $33.7 \%$ & Urban & 352 & $87.1 \%$ \\
\hline Marital Status & & & Self-Reported Health Status & & \\
\hline Single & 158 & $39.1 \%$ & Very bad & 2 & $.5 \%$ \\
\hline Married & 213 & $52.7 \%$ & bad & 39 & $9.7 \%$ \\
\hline Divorced & 20 & $5.0 \%$ & Not bad & 105 & $26.0 \%$ \\
\hline Widowed & 13 & $3.2 \%$ & good & 225 & $55.7 \%$ \\
\hline Educational status & & & Very good & 33 & $8.2 \%$ \\
\hline No formal Education & 15 & $3.7 \%$ & Follow-up in years & & \\
\hline Primary education & 60 & $14.9 \%$ & $<1$ & 105 & $26.0 \%$ \\
\hline Secondary education & 121 & $30.0 \%$ & $1-3$ & 136 & $33.7 \%$ \\
\hline Diploma and above & 208 & $51.5 \%$ & $3-5$ & 49 & $12.1 \%$ \\
\hline Type of Chronic Disease & & & $>5$ & 114 & $28.2 \%$ \\
\hline CVD & 143 & $35.4 \%$ & Frequency of internet use & & \\
\hline CRD & 24 & $5.9 \%$ & Daily & 190 & $47.0 \%$ \\
\hline Diabetes & 141 & $34.9 \%$ & Several days a week & 163 & $40.3 \%$ \\
\hline Epilepsy & 52 & $12.9 \%$ & One day a week & 28 & $7.0 \%$ \\
\hline Others & 44 & $10.9 \%$ & Less than one day a week & 23 & $5.7 \%$ \\
\hline \multicolumn{6}{|l|}{ Monthly Income* } \\
\hline$<800$ & 118 & $29.2 \%$ & & & \\
\hline $800-1500$ & 62 & $15.3 \%$ & & & \\
\hline 1500-3500 & 99 & $24.5 \%$ & & & \\
\hline $3500-5500$ & 65 & $16.1 \%$ & & & \\
\hline$>5500$ & 60 & $14.9 \%$ & & & \\
\hline
\end{tabular}

* The monthly income currency is in Ethiopian Birr (ETB)

among youngsters which is related with internet using habit [42].

when compared to studies conducted in other countries, the mean eHealth literacy score of chronic patients in this study was relatively lower and this could be due to the less internet penetration and economic berries in low-income countries like Ethiopia [43-45]. The univariate analysis indicated that patient's educational status, occupation type, permanent residence, self-reported health status, monthly salary, frequency of internet use, knowledge about the availability and importance of online health information resources, attitude towards using online sources and computer literacy level of participants were significantly associated with eHealth literacy skill with $95 \%$ confidence interval, $(p$-value $<0.05)$. After adjustment for the covariates, except for two variables (residence and frequency of internet use) all the other predictor variables were significantly associated with eHealth literacy skill with $p$-value $<0.05$. See Table 2 for detail. Patients with diploma and above education level were 3.48 (CI: 1.54, 7.87) times more likely to have high eHealth literacy skill compared with those with primary and below education level ( $p$-value $<0.05)$. This finding is similar with other studies in different populations which underlined the need for capacity building and continuous educational support for chronic patients with lower educational status $[15,46,47]$. Participants who works in governmental organizations were more likely to possess high eHealth literacy when compared to unemployed chronic patients with AOR: 1.73, 95\%CI: (1.11, 2.68). This study also indicated that chronic patients living in urban setting are COR: 3.77 (95\%CI: $(1.88,7.57)$ 
Table 2 Factors associated with eHealth literacy among chronic patients in UOGCSH

\begin{tabular}{|c|c|c|c|c|c|c|}
\hline \multirow{2}{*}{$\frac{\text { Independent Variable }}{\text { Educational Status }}$} & \multicolumn{2}{|c|}{ eHealth literacy skill } & \multirow[t]{2}{*}{$\operatorname{COR}(\mathrm{Cl})$} & \multirow{2}{*}{$\frac{P \text {-value }}{<0.001}$} & \multirow[t]{2}{*}{$\mathrm{AOR}(\mathrm{Cl})$} & \multirow{2}{*}{$\frac{P \text {-value }}{0.006}$} \\
\hline & low & high & & & & \\
\hline Primary education and below & 52 & 23 & 1 & & & \\
\hline Secondary education & 84 & 37 & $0.99(0.53,1.86)$ & 0.892 & $1.71(0.74,3.96)$ & 0.214 \\
\hline Diploma and above & 80 & 128 & $3.62(2.06,6.36)$ & $<0.001$ & $3.48(1.54,7.87)$ & 0.003 \\
\hline Occupation Type & & & & 0.037 & & 0.019 \\
\hline Governmental job & 69 & 81 & $1.85(1.16,2.95)$ & 0.024 & $1.73(1.11,2.68)$ & 0.006 \\
\hline Privet job & 62 & 53 & $1.35(0.82,2.22)$ & 0.058 & $1.02(0.89,1.67)$ & 0.314 \\
\hline unemployed & 85 & 54 & 1 & & & \\
\hline \multicolumn{7}{|l|}{ Residence } \\
\hline urban & 175 & 177 & $3.77(1.88,7.57)$ & $<0.001$ & $1.37(0.54,3.49)$ & 0.09 \\
\hline rural & 41 & 11 & 1 & & & \\
\hline Self-reported health status & & & & $<0.001$ & & $<0.001$ \\
\hline bad & 32 & 9 & 1 & & & \\
\hline Not bad & 66 & 39 & $2.10(0.91,4.86)$ & 0.08 & $1.36(0.45,4.14)$ & 0.058 \\
\hline good & 118 & 140 & $4.23(1.94,9.19)$ & $<0.001$ & $3.97(1.38,11.38)$ & 0.01 \\
\hline Monthly income* & & & & $<0.001$ & & 0.003 \\
\hline$<800$ & 70 & 48 & 1 & & & \\
\hline $800-1500$ & 40 & 22 & $0.80(0.42,1.52)$ & 0.12 & $0.59(0.22,1.57)$ & 0.12 \\
\hline $1500-3500$ & 68 & 31 & $0.67(0.38,1.17)$ & 0.15 & $0.62(0.24,1.59)$ & 0.08 \\
\hline $3500-5500$ & 28 & 37 & $1.93(1.04,3.56)$ & 0.036 & $1.38(0.52,3.73)$ & 0.042 \\
\hline$>5500$ & 10 & 50 & $7.29(3.37,15.78)$ & $<0.001$ & $4.44(1.32,14.86)$ & 0.016 \\
\hline Frequency of internet use & & & & $<0.001$ & & 0.06 \\
\hline Daily & 88 & 102 & $4.78(2.18,10.45)$ & $<0.001$ & $2.96(1.08,6.76)$ & 0.042 \\
\hline Several days a week & 92 & 71 & $3.22(1.46,7.10)$ & 0.004 & $1.81(0.71,4.6)$ & 0.086 \\
\hline One day and less than one day in a week & 36 & 15 & 1 & & & \\
\hline \multicolumn{7}{|l|}{ Knowledge } \\
\hline Good Knowledge & 54 & 121 & $5.42(3.53,8.32)$ & $<0.001$ & $3.12(1.61,5.3)$ & $<0.001$ \\
\hline Poor knowledge & 162 & 67 & 1 & & & \\
\hline \multicolumn{7}{|l|}{ Attitude } \\
\hline Favorable Attitude & 49 & 110 & $4.81(3.12,7.39)$ & $<0.001$ & $2.94(1.07,3.52)$ & 0.029 \\
\hline Unfavorable attitude & 167 & 78 & 1 & & & \\
\hline \multicolumn{7}{|l|}{ Computer literacy } \\
\hline High computer literacy & 41 & 128 & $9.11(5.76,14.39)$ & $<0.001$ & $3.81(2.19,6.61)$ & $<0.001$ \\
\hline Low computer literacy & 175 & 60 & 1 & & & \\
\hline
\end{tabular}

*Monthly income currency is in Ethiopian Birr

times more likely to possess high eHealth literacy skill compared to patients residing on rural setting. The finding seems obvious in most cases $[48,49]$ but it is different in developed countries in which majority of rural patients have computer and internet connection in their home preferring internet for health information [50-52]. Income was the other significant factor associated with eHealth literacy skill among chronic patients in which patients those who have a monthly income $>5500$ ETB are more likely to have higher eHealth literacy skill compared with those who earn monthly income $<800$ ETB with AOR:4.44, (95\%CI, 1.32, 14.86), $P$-value $<0.05$. Higher income is highly associated with higher eHealth literacy skill in different studies [53, 54]. In this study, patients who perceived their health status as good were 3.97 times more likely to have higher eHealth literacy skill with 95\% CI: $(1.38,11.38)$ and $p$-value $<0.05$ compared to those who perceive their health status as bad. This finding is similar with other studies done elsewhere which argues the more likely possession of eHealth 
literacy skill by patients who perceive their health status as good [30, 55, 56]. This could be due to the fact that peoples with perceived good health condition are more likely to be looking for possible medical treatment and preventive actions before their health get worse. Frequency of internet use was also the predictive variable with $p$-value $<0.05$ where chronic patients those who use internet on a daily basis are almost 3 (AOR: 2.96) times more likely to have high eHealth literacy skill when compared to those who use internet 1 day and less than 1 day a week with $95 \% \mathrm{CI}$ : $(1.08,6.76)$. This finding is similar with different studies confirming that frequent internet users possess higher eHealth literacy skill [15, $30,57,58]$. In addition, higher computer literacy was also highly associated with higher eHealth literacy skill which is similar with studies done elsewhere [59-61]. Knowledge regarding the availability and importance of health information and attitude toward using online resources were significant factors associated with eHealth literacy skill where patients with good knowledge and favorable attitude toward online resources are more likely to possess high eHealth literacy skill with AOR: 3.12, 95\% CI: $(1.61,5.3)$ and AOR: $2.94,95 \%$ CI: $(1.07,3.52)$ respectively. This finding was also in line with other studies [62-65].

\section{Conclusion}

This study found that educational status, perceived health status, income and frequency of internet use have significant impact on consumers eHealth literacy skill confirming with several studies. It also suggested other factors like knowledge about availability and importance of online sources, attitude and computer literacy are important variables associated with eHealth literacy level in this population. Internet use and eHealth literacy level of chronic patients in this setting is relatively low. This clearly implicate the need to fill the skill gap in eHealth literacy among chronic patients which may help them in building their capacity to find and evaluate relevant online sources for their health-related decisions.

\section{Limitation of the study}

As this is the first study to investigate eHealth literacy and associated factors among chronic patients in resource limited settings, there were limitations identified for further investigators. This limitation of this study is that more than half of the study participants were from urban resident setting and all participants were selected after confirming their previous internet exposure. Those with previous internet exposure were interviewed further and those who doesn't know about the internet were excluded. This could have caused a selection bias where urban residing and internet user participants are more likely to possess high eHealth literacy. The other limitation of this study was the small sample size \& it was conducted in a single institution in Northern Ethiopia. Therefore, the results may not be generalizable to all chronic patients and future researchers should consider more broader samples from different clusters of populations in the country to ensure generalizability.

\section{Practical implications}

Considering the importance of chronic patients' ability to find and evaluate health information for their health management decisions, it is highly important for the Ethiopian Federal ministry of health and other responsible bodies to consider methodical approach to improve the eHealth literacy skill of internet user chronic patients through short trainings and education. Hospitals should also consider facilitating health care providers advisory of online sources for their patients. It is also important for future researchers to consider exploring other relevant factors associated with eHealth literacy skill of chronic patients.

\section{Supplementary information}

Supplementary information accompanies this paper at https://doi.org/10. 1186/s12911-020-01202-1.

Additional file 1.

Abbreviations

eHEALS: eHealth Literacy Scale; AOR: Adjusted Odds Ratio; Cl: Confidence Interval; NCDs: Noncommunicable Diseases; WHO: World Health Organization; eHealth: Electronic Health; UOGCSH: University of Gondar Comprehensive Specialized Hospital; SPSS: Statistical Package for Social Science; VIF: Variance Inflation Factor; OR: Odds Ratio; CVD: Cardiovascular Diseases; CRD: Chronic Respiratory Diseases; COR: Crude Odds Ratio

\section{Acknowledgements}

The authors would like to thank University of Gondar, University of Gondar comprehensive specialized hospital administrative staffs and e-health lab Ethiopia for their support and collaboration.

\section{Authors' contributions}

KB made significant contributions in conception, design, data collection supervision, data analysis, interpretation and writeup of the manuscript. BC \& BF have contributed in extensively revising the manuscript, analysis and interpretation as well. MK \& SA was involved in drafting the manuscript and revising it critically for important intellectual content and all authors have approved the final version of this manuscript.

\section{Funding}

This study was financed by University of Gondar research and community service Directorate \& CBMP project eHealth lab Ethiopia. The funding offices had no direct or indirect involvement in the study writeup and analysis, it was only involved in budgeting and budget evaluation.

Availability of data and materials

All data generated or analyzed during this study are included in this published article.

\section{Ethics approval and consent to participate}

Ethical clearance for this study was secured from University of Gondar, College of medicine and health science ethical review board. Necessary permission was obtained from the hospital director and written informed consent was obtained from study participants. 


\section{Consent for publication}

Not applicable.

\section{Competing interests}

The authors declare that they have no competing interests.

\section{Author details}

'Health Informatics Department, Medicine and Health science college, Debre Markos University, Debre Markos, Ethiopia. ${ }^{2}$ Health Informatics Department, College of Medicine and Health science, University of Gondar, Gondar, Ethiopia. ${ }^{3}$ Faculty of Health \& Social Sciences, Science center Health \& Technology, University of South-Eastern Norway, Notodden, Norway. ${ }^{4}$ School of Business, Institute of Business, History \& Social Sciences, University of South-Eastern Norway, Notodden, Norway.

\section{Received: 24 January 2020 Accepted: 23 July 2020}

\section{Published online: 06 August 2020}

\section{References}

1. Noncommunicable diseases [https://www.who.int/news-room/fact-sheets/ detail/noncommunicable-diseases].

2. Global Health Observatory (GHO) data [https://www.who.int/gho/countries/ eth/country_profiles/en/].

3. Noncommunicable diseases [https://www.who.int/en/news-room/factsheets/detail/noncommunicable-diseases].

4. Castro EM, Van Regenmortel T, Vanhaecht K, Sermeus W, Van Hecke A. Patient empowerment, patient participation and patient-centeredness in hospital care: a concept analysis based on a literature review. Patient Educ Couns. 2016;99(12):1923-39.

5. Fotokian Z, Mohammadi Shahboulaghi F, Fallahi-Khoshknab M, Pourhabib A. The empowerment of elderly patients with chronic obstructive pulmonary disease: managing life with the disease. PLoS One. 2017;12(4): e0174028.

6. Ha Dinh TT, Bonner A, Clark R, Ramsbotham J, Hines S. The effectiveness of the teach-back method on adherence and self-management in health education for people with chronic disease: a systematic review. JBI Database System Rev Implement Rep. 2016;14(1):210-47.

7. Powers MA, Bardsley J, Cypress M, Duker P, Funnell MM, Fischl AH, Maryniuk $M D$, Siminerio L, Vivian E. Diabetes self-management education and support in type 2 diabetes:a joint position statement of the American Diabetes Association, the American Association of Diabetes Educators, and the academy of nutrition and dietetics. Diab Educ. 2017:43(1):40-53.

8. Dwarswaard J, Bakker EJM, van Staa A, Boeije HR. Self-management support from the perspective of patients with a chronic condition: a thematic synthesis of qualitative studies. Health Expect. 2016;19(2):194-208.

9. Briggs JS, Early GH. Internet developments and their significance for healthcare. Med Inform Internet Med. 1999;24(3):149-64.

10. Gray M. Making the future of healthcare. Z Evid Fortbild Qual Gesundhwes. 2008;102(4):231-3.

11. Duff O, Walsh D, Furlong B, O'Connor N, Moran KA, Woods C. Behavior Change Techniques in Physical Activity eHealth Interventions for People With Cardiovascular Disease: Systematic Review. J Med Internet Res. 2017; 19(8):e281.

12. Simonse L. Information and Communication Technology-Enabled PersonCentered Care for the "Big Five" Chronic Conditions: Scoping Review. J Med Internet Res. 2015;17(3):e77.

13. Picton P, Urowitz S, Wiljer D, Cafazzo J. Engaging Patients in Online SelfCare Technologies for Chronic Disease Management. Healthcare quarterly (Toronto, Ont.). 2016;18(4):55-61.

14. Willis E, Royne MB. Online health communities and chronic disease selfmanagement. Health Commun. 2017;32(3):269-78.

15. Richtering SS, Hyun K, Neubeck L, Coorey G, Chalmers J, Usherwood T, Peiris D, Chow CK, Redfern J. eHealth literacy: predictors in a population with moderate-to-high cardiovascular risk. JMIR Hum Factors. 2017;4(1):e4.

16. Melholt $\mathrm{C}$, Joensson $\mathrm{K}$, Spindler $\mathrm{H}$, Hansen J, Andreasen JJ, Nielsen G, Noergaard A, Tracey A, Thorup C, Kringelholt R, et al. Cardiac patients' experiences with a telerehabilitation web portal: implications for eHealth literacy. Patient Educ Couns. 2018;101(5):854-61.

17. Norman C, Skinner H. EHealth Literacy: Essential Skills for Consumer Health in a Networked World. J Med Internet Res. 2006;8(2):e9.
18. Griebel L, Enwald H, Gilstad H, Pohl A-L, Moreland J, Sedlmayr M. eHealth literacy research—quo vadis? Inform Health Soc Care. 2018;43(4):427-42.

19. Norman CD, Skinner HA. eHealth literacy: essential skills for consumer health in a networked world. J Med Internet Res. 2006;8(2):e9.

20. TW LN, Rusli BN. Practical Issues in Calculating the Sample Size for Prevalence Studies. Arch Orofac Sci. 2006;1:9-14.

21. Pourhoseingholi MA, Vahedi M, Rahimzadeh M. Sample size calculation in medical studies. Gastroenterol Hepatol Bed Bench. 2013;6(1):14-7.

22. Suresh K, Thomas SV, Suresh G. Design, data analysis and sampling techniques for clinical research. Annals of Indian Academy of Neurol. 2011; 14(4):287.

23. Norman CD, Skinner HA. eHEALS: the eHealth literacy scale. J Med Internet Res. 2006;8(4):e27.

24. Richtering SS, Morris R, Soh S-E, Barker A, Bampi F, Neubeck L, Coorey G, Mulley J, Chalmers J, Usherwood T, et al. Examination of an eHealth literacy scale and a health literacy scale in a population with moderate to high cardiovascular risk: Rasch analyses. PLoS One. 2017;12(4):e0175372.

25. Duplaga M. A cross-sectional study assessing determinants of the attitude to the introduction of eHealth services among patients suffering from chronic conditions. BMC Med Inform Decis Mak. 2015;15(1):33.

26. Neter $\mathrm{E}$, Brainin E. eHealth literacy: extending the digital divide to the realm of health information. J Med Internet Res. 2012;14(1):e19.

27. Paige SR, Stellefson M, Krieger JL, Anderson-Lewis C, Cheong J, Stopka C. Proposing a transactional model of eHealth literacy: concept analysis. J Med Internet Res. 2018:20(10):e10175.

28. Koopman RJ, Petroski GF, Canfield SM, Stuppy JA, Mehr DR. Development of the PRE-HIT instrument: patient readiness to engage in health information technology. BMC Fam Pract. 2014;15(1):18.

29. van der Vaart R, Drossaert C. Development of the Digital Health Literacy Instrument: Measuring a Broad Spectrum of Health 1.0 and Health 2.0 Skills. J Med Internet Res. 2017;19(1):e27.

30. Vicente MR, Madden G. Assessing eHealth skills across Europeans. Health Policy Technol. 2017;6(2):161-8.

31. Tubaishat $A$, Habiballah L. eHealth literacy among undergraduate nursing students. Nurse Educ Today. 2016;42:47-52.

32. Tissera S, Silva N. Self-reported eHealth literacy among undergraduate nursing students in selected districts of Sri Lanka. Stud Health Technol Inform. 2017;245:1339.

33. Norman C. eHealth Literacy 2.0: Problems and Opportunities With an Evolving Concept. J Med Internet Res. 2011;13(4):e125.

34. Kim KA, Kim YJ, Choi M. Association of Electronic Health Literacy with Health-Promoting Behaviors in patients with type 2 diabetes: a crosssectional study. Comput Inform Nurs. 2018;36(9):438-47.

35. James DCS, Harville C II. eHealth literacy, online help-seeking behavior, and willingness to participate in mHealth chronic disease research among African Americans, Florida, 2014-2015. Prev Chronic Dis. 2016;13:E156.

36. Halwas N, Griebel L, Huebner J. eHealth literacy, Internet and eHealth service usage: a survey among cancer patients and their relatives. J Cancer Res Clin Oncol. 2017;143(11):2291-9.

37. Perneger TV, Courvoisier D, Hudelson P, Gayet-Ageron A. Sample size for pre-tests of questionnaires. Qual Life Res. 2015;24(1):147-51.

38. O'brien RM. A caution regarding rules of thumb for variance inflation factors. Qual Quant. 2007:41(5):673-90.

39. Hosmer DW Jr, Lemeshow S, Sturdivant RX. Applied logistic regression, Vol. 398. Wiley; 2013.

40. Mickey RM, Greenland S. The impact of confounder selection criteria on effect estimation. Am J Epidemiol. 1989;129(1):125-37.

41. Chen W, Wellman B. The global digital divide-within and between countries. It Society. 2004;1(7):39-45.

42. Loges WE, Jung J-Y. Exploring the digital divide: internet connectedness and age. Commun Res. 2001;28(4):536-62.

43. Paige SR, Krieger JL, Stellefson M, Alber JM. eHealth literacy in chronic disease patients: an item response theory analysis of the eHealth literacy scale (eHEALS). Patient Educ Couns. 2017;100(2):320-6.

44. Milne RA, Puts MT, Papadakos J, Le LW, Milne VC, Hope AJ, Catton P, Giuliani ME. Predictors of high eHealth literacy in primary lung Cancer survivors. J Cancer Educ. 2015;30(4):685-92.

45. Richtering SS, Hyun K. eHealth Literacy: Predictors in a Population With Moderate-to-High Cardiovascular Risk. JMIR human factors. 2017:4(1):e4. 
46. Martinez CH, St Jean BL, Plauschinat CA, Rogers B, Beresford J, Martinez FJ, Richardson CR, Han MK. Internet access and use by COPD patients in the National Emphysema/COPD association survey. BMC Pulm Med. 2014;14:66.

47. Paige SR, Stellefson M, Chaney BH, Chaney DJ, Alber JM, Chappell C, Barry AE. Examining the relationship between online social capital and eHealth literacy: implications for Instagram use for chronic disease prevention among college students. Am J Health Educ. 2017;48(4):264-77.

48. Zhang WJ, Xue L, Chen R, Duan ZQ, Liu DP. Medical Service Information Seeking Behaviors in Rural and Urban Patients in Sichuan Province, Sichuan Da Xue Xue Bao Yi Xue Ban. 2018;49(2):271-5.

49. Nedungadi P, Jayakumar A, Raman R. Personalized health monitoring system for managing well-being in rural areas. J Med Syst. 2017;42(1):22.

50. Quin J, Stams V, Phelps B, Boley T, Hazelrigg S. Interest in internet lung cancer support among rural cardiothoracic patients. J Surg Res. 2010;160(1):35-9.

51. Fennell KM, Turnbull DA, Bidargaddi N, McWha UL, Davies M, Olver I. The consumer-driven development and acceptability testing of a website designed to connect rural cancer patients and their families, carers and health professionals with appropriate information and psychosocial support. Eur J Cancer Care. 2017;26(5):e12533.

52. Modipane MB, Waldman AL, Ritterband L, Dillingham R, Bullock L, Ingersoll KS. Technology use among patients in a nonurban southern U.S. HIV clinic in 2015. Telemed J E Health. 2016:22(11):965-8.

53. Arcury TA, Sandberg JC, Melius KP, Quandt SA, Leng X, Latulipe C, Miller DP Jr, Smith DA, Bertoni AG. Older adult internet use and eHealth literacy. J Appl Gerontol. 2018; 733464818807468.

54. Chesser A, Burke A, Reyes J, Rohrberg T. Navigating the digital divide: a systematic review of eHealth literacy in underserved populations in the United States. Inform Health Soc Care. 2016;41(1):1-19.

55. Richtering SS, Hyun K, Neubeck L, Coorey G, Chalmers J, Usherwood T, Peiris D, Chow C, Redfern J. eHealth Literacy: Predictors in a Population With Moderate-to-High Cardiovascular Risk. JMIR human factors. 2017;4(1):e4.

56. McInnes D, Gifford A, Kazis LE, Wagner T. Disparities in health-related Internet use by US veterans: Results from a national survey. J Innov Health Informatics. 2010;18(1):59-68.

57. van Beugen S, Ferwerda M, Hoeve D, Rovers MM, Koulil S, van Middendorp H, Wm Evers A. Internet-Based Cognitive Behavioral Therapy for Patients With Chronic Somatic Conditions: A Meta-Analytic Review. J Med Internet Res. 2014;16(3):e88.

58. Villani D, Cognetta C, Repetto C, Serino S, Toniolo D, Scanzi F, Riva G. Promoting emotional well-being in older breast Cancer patients: results from an eHealth intervention. Front Psychol. 2018;9:2279.

59. Chang FC, Chiu CH, Chen PH, Miao NF, Lee CM, Chiang JT, Pan YC. Relationship between parental and adolescent eHealth literacy and online health information seeking in Taiwan. Cyberpsychol Behav Soc Netw. 2015; 18(10):618-24

60. Kim SH, Son YJ. Relationships between eHealth literacy and health behaviors in Korean adults. Comput Inform Nurs. 2017;35(2):84-90.

61. Monkman H, Griffith J, Kushniruk AW. Evidence-based heuristics for evaluating demands on eHealth literacy and usability in a Mobile consumer health application. Stud Health Technol Inform. 2015;216:358-62.

62. Dutta-Bergman M. Trusted online sources of health information: differences in demographics, health beliefs, and health-information orientation. J Med Internet Res. 2003;5(3):e21.

63. Coyne I, Prizeman G, Sheehan A, Malone H, While AE. An e-health intervention to support the transition of young people with long-term illnesses to adult healthcare services: design and early use. Patient Educ Couns. 2016;99(9):1496-504.

64. Stellefson ML, Shuster JJ, Chaney BH, Paige SR, Alber JM, Chaney JD, Sriram PS. Web-based health information seeking and eHealth literacy among patients living with chronic obstructive pulmonary disease (COPD). Health Commun. 2018:33(12):1410-24.

65. Talboom-Kamp EPWA, Verdijk NA, Kasteleyn MJ, Numans ME, Chavannes $\mathrm{NH}$. From chronic disease management to person-centered eHealth; a review on the necessity for blended care. Clin eHealth. 2018;1(1):3-7.

\section{Publisher's Note}

Springer Nature remains neutral with regard to jurisdictional claims in published maps and institutional affiliations.

\section{Ready to submit your research? Choose BMC and benefit from:}

- fast, convenient online submission

- thorough peer review by experienced researchers in your field

- rapid publication on acceptance

- support for research data, including large and complex data types

- gold Open Access which fosters wider collaboration and increased citations

- maximum visibility for your research: over $100 \mathrm{M}$ website views per year

At $\mathrm{BMC}$, research is always in progress.

Learn more biomedcentral.com/submissions 